\title{
Surgical Skills Workshops Should Be a Part of the United Kingdom Undergraduate Medical Curriculum
}

Muhammad A. Hakim ${ }^{1}$, Elizabeth D. Dominguez ${ }^{2}$, Sebastian Priest ${ }^{1}$, Keng Siang Lee ${ }^{1}$, Ameen Mardanpour ${ }^{1}$, Sankalp Tandle ${ }^{1}$, Majid Al-Khalil ${ }^{1}$, George Slade ${ }^{1}$, Sameer Gujral ${ }^{3}$

1. Health Sciences, University of Bristol Medical School, Bristol, GBR 2. Orthopaedics, University of Bristol Medical School, Bristol, GBR 3. Plastic Surgery, Southmead Hospital, Bristol, GBR

$\square$ Corresponding author: Muhammad A. Hakim, mah160992@gmail.com Disclosures can be found in Additional Information at the end of the article

\section{Abstract}

Introduction: Medical students across the United Kingdom (UK) report poor satisfaction with surgical teaching. The Surgical Skills Day (SSD) begins to address this by exposing medical students to surgery through an easily accessible one-day practical workshop. This study shows how the SSD encourages undergraduate engagement in surgery.

Method: Feedback forms were emailed to attendees of the SSD and their anonymised responses were used to evaluate the SSD.

Results: A total of 144 students attended the SSD across three years and the feedback response rate was $74 \%(n=107)$. Key findings were that $100 \%$ of respondents $(n=107)$ would like the SSD to be an annual event, $79 \%(n=83)$ were more inclined to pursue a surgical career following the event, and $97 \%(n=103)$ would like to see practical surgical skills incorporated into the curriculum. The SSD was able to engage undergraduates with surgery through mentorship, practical skills, specialty exposure, and teaching of the General Medical Council (GMC) mandated skills.

Conclusions: Undergraduate surgical teaching in the UK is insufficient. The student-led annual SSD showed improved engagement in practical surgical skills and increased enthusiasm for a surgical career. In light of this, the authors feel the SSD or similar event should be integrated into the UK medical school curriculum.

Received 03/08/2019

Review began 03/17/2019

Review ended 04/25/2019

Published 05/11/2019

(C) Copyright 2019

Hakim et al. This is an open access article distributed under the terms of the Creative Commons Attribution License CC-BY 3.0., which permits unrestricted use, distribution, and reproduction in any medium, provided the original author and source are credited.
Categories: Medical Education, Medical Simulation, General Surgery

Keywords: surgical skills, teaching, workshops, medical student curriculum, undergraduate education, united kingdom (uk)

\section{Introduction}

In 2015, the Royal College of Surgeons (RCS) of England highlighted the need for a robust undergraduate surgical education [1]. However, medical students across the United Kingdom (UK) report poor satisfaction with surgical teaching and inadequate preparation for surgical rotations during foundation training when compared to medical rotations [2-4]. Furthermore, many junior doctors lack competency in basic surgical skills, such as skin suturing, which are mandated by the General Medical Council (GMC) for all newly qualified UK doctors [5-8]. 


\section{Cureus}

Surgical skills workshops are a promising initiative to compensate for the aforementioned lack of formal undergraduate surgical education; it not only improves medical students' proficiency in suturing but also exposes them to surgical specialties and stimulates their interests in surgery as a career option [9-10].

The annual Surgical Skills Day (SSD), organised by the University of Bristol Surgery Society (SCRUBS), is a student-led surgical skills workshop. This article reports conclusions from three annual SSDs (2016 - 2018), based on feedback from the University of Bristol medical students.

\section{Materials And Methods}

The SSD is a one-day practical course aimed at the University of Bristol medical students. The day is comprised of a range of diverse practical surgical skill stations, each one hour in duration. The instructors running the workshop stations are surgeons of different grades from trainee to consultant level. The event was priced at five pounds (lunch inclusive) to help with equipment hire and food purchase. Across the three years of running the SSD, workshop stations have included laparoscopic simulation, dynamic hip screw placement using model femurs, burr hole drilling on model skulls, tracheostomy insertion on mannequins, trauma scenarios focusing on conducting a primary survey, porcine aortic re-anastomosis, tendon repair, and suturing using porcine models (see Table 1 below for details on stations provided each year). After completion of the SSD, attendees were asked to complete an anonymised feedback form (see Appendix) in exchange for a certificate of workshop completion, to incentivise students to provide feedback.

\section{Year Workshop Stations}

2016 Suturing, Dynamic Hip Screw, Laparoscopic Simulation, Burr Hole Drilling, Trauma Scenarios

2017 Suturing, Dynamic Hip Screw, Laparoscopic Simulation, Tendon Repair

2018 Suturing, Laparoscopic Simulation, Tendon Repair, Aortic Re-Anastomosis, Tracheostomy

TABLE 1: Different Workshop Stations for 2016-2018

\section{Results}

We have listed some of the key details below from the 2016 - 2018 SSD feedback responses.

Over the course of three years, an average of 48 participants (2016 - 2018 average (standard deviation (SD): 6.48)) attended the SSD each year for a total of 144 students. In 2016, 57 students attended, with 42 in 2017 and 45 in 2018. The mean response rate for feedback was $74 \%(\mathrm{n}=107)(2016-2018$ average (SD: 10.5)). Attendance was divided 47\% $(\mathrm{n}=50)$ and 53\% (n = 56) between males and females (2016 - 2018 average (SD: 1.83)), respectively. The percentage of students either in the first, second, or third year was an average of $64 \%(n=68)$; the remaining $36 \%(n=38)$ of attendees were in their fourth or fifth year of study (2016 - 2018 average (SD: 13.9$)$ ).

Figure 1 below shows student responses across the three years to key questions of the feedback form. 


\section{Cureus}

Would you like to see practical surgical skills as part of the medical school curriculum?

Would you want to see the SSD as a yearly event?

Would you recommend the SSD to a friend?

Following the SSD, are you more likely to pursue a career in surgery?

$0 \%$

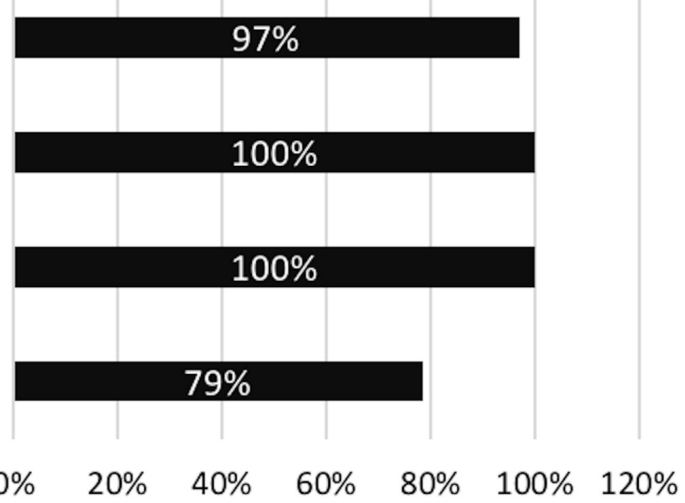

FIGURE 1: Bar graph depicting the percentage of students who answered "yes" to the following questions

The feedback questionnaire required attendees to score each workshop station for overall satisfaction, on a rating scale of 1 to 10 , with 10 being the highest. The mean rating for each station is shown below in Figure 2.

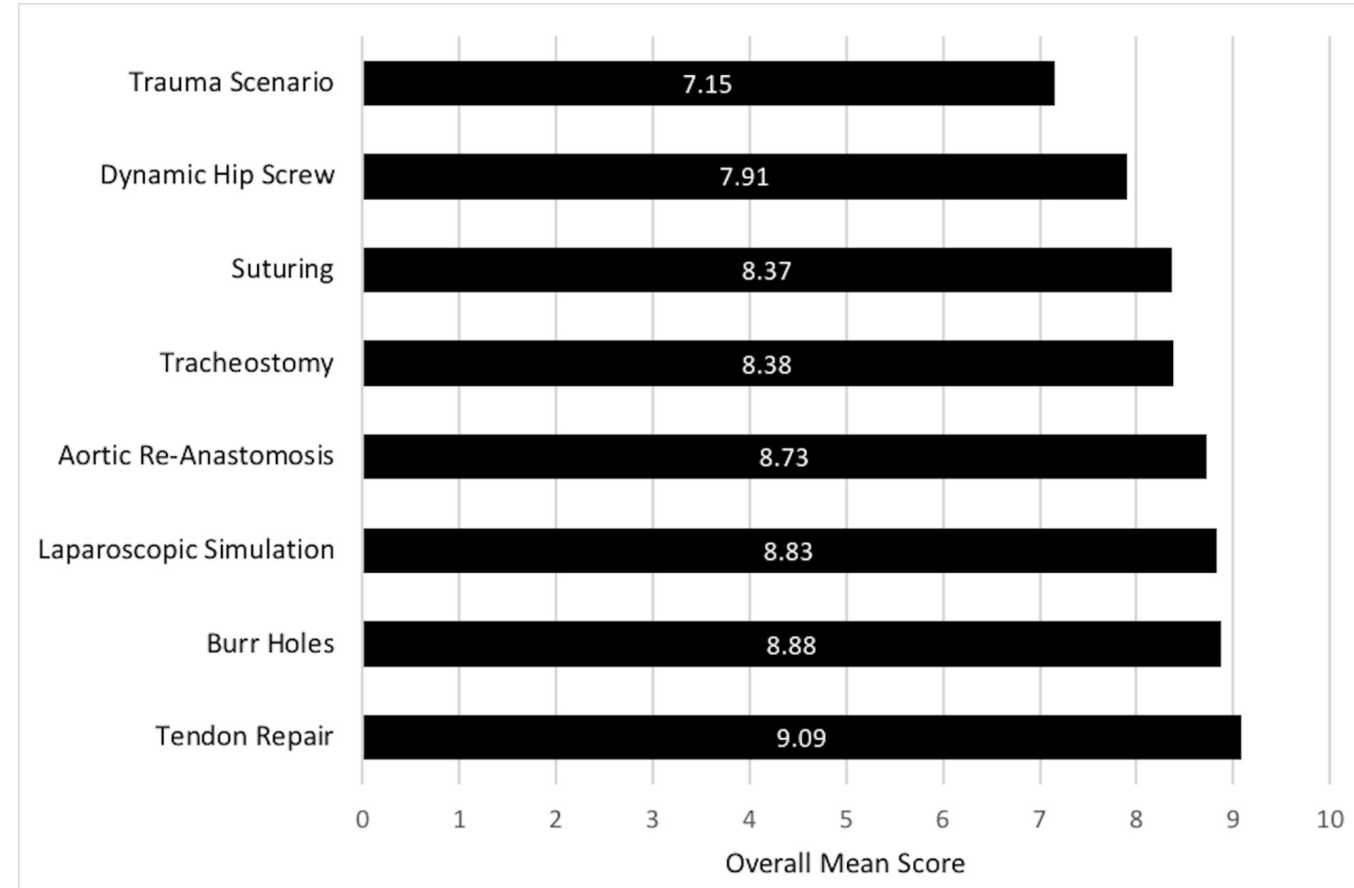

FIGURE 2: Mean rating (on a scale of 1 to 10) for overall satisfaction of each workshop station

The feedback questionnaire asked students to comment on the surgeons who were instructing the workshops. Table 2 below shows the percentage of positive and negative comments regarding instructor performance for the 2018 SSD. Feedback comments for instructor performance and interactions are detailed below in Table 3 (2016 and 2017 data cannot be provided as instructor performance was not assessed during these years). 


\section{Cureus}

\section{Category}

Positive comments

Negative comments
Number of Responses (\%)

$48(71.5)$

$20(28.5)$

\section{TABLE 2: Feedback Comments on Instructors for the 2018 Surgical Skills Day}

Quantitative analysis of comments in response to: 'Please comment on the Suturing instructor(s). What did they do well and what could they improve on?'

\section{Category}

Excellent quality of tuition

Approachable, informative, and supportive tutor

Provided the opportunity to develop previously learned skills

Positively challenging, i.e., 'Pushing us to get better'

Total (positive comments)

Lack of/unsuitable equipment provided

Should allocate groups based on ability

Should improve guidance

More tutors should have been available

Should have featured a small theoretical introduction

Not appropriate for training level, i.e., 'I didn't learn anything new'

Total (negative comments)
Number of Responses (\%)

$51(47.9)$

$15(14.3)$

$7(6.30)$

$4(4.20)$

$78(72.7)$

7 (6.30)

$7(6.30)$

$7(6.30)$

$4(4.20)$

$2(2.10)$

$2(2.10)$

$29(27.3)$

Quantitative analysis of comments in response to: 'Please comment on the ENT instructor(s). What did they do well and what could they improve on?'

Category

Synthesis of theoretical and practical elements

Excellent quality of tuition

Approachable, informative, and supportive tutor

Excellent group size, i.e., 'Small groups were helpful'

Tuition relevant to studies

Total (positive comments)
Number of Responses (\%)

$12(30.0)$

$7(17.5)$

$6(15.0)$

$2(5.00)$

$1(2.50)$

$28(70.0)$ 


\section{Cureus}

Should improve time management, i.e., 'We ran out of time'

Not enough practical elements

Lack of/unsuitable equipment provided

Not appropriate for training level, i.e., 'I didn’t learn anything new'

Total (negative comments)
$8(2.00)$

$3(7.50)$

$1(2.50)$

$12(30.0)$

Quantitative analysis of comments in response to: 'Please comment on the Laparoscopic instructor(s). What did they do well and what could they improve on?'

Category

Approachable, informative, and supportive tutor

Should improve guidance

Excellent quality of tuition

Challenging and competitive aspects provided

Tuition relevant to studies

Good range of equipment

Total (positive comments)

Should improve time management, i.e., 'We ran out of time'

More tutors should have been available

Clinical applications not made clear

Total (negative comments)
Number of Responses (\%)

$30(28.0)$

$20(19.0)$

$15(14.0)$

$13(12.1)$

$5(4.67)$

$5(4.67)$

$69(64.5)$

$8(7.48)$

$38(35.5)$

Quantitative analysis of comments in response to: 'Please comment on the Plastics instructor(s). What did they do well and what could they improve on?'

\section{Category}

Excellent quality of tuition

Approachable, informative, and supportive tutor

Synthesis of theoretical and practical elements

Positively challenging, i.e., 'Pushing us to get better'

Total (positive comments)

Not enough variety of skills taught

Should improve guidance

Assumed too much previous knowledge

Lack of information on specialty provided by tutors

Intensity of the tuition too high
Number of Responses (\%)

$15(31.9)$

$13(27.7)$

$3(6.38)$

$2(4.26)$

$33(70.2)$

$3(6.38)$

$3(6.38)$

$2(4.26)$

$2(4.26)$ 


\section{Cureus}

Total (negative comments)

$14(29.8)$

Quantitative analysis of comments in response to: 'Please comment on the Vascular instructor(s). What did they do well and what could they improve on?'

\section{Category}

Excellent quality of tuition

Approachable, informative, and supportive tutor

Tuition relevant to studies

Opportunity to develop previously learned skills

Total (positive comments)

Should improve guidance

Lack of/unsuitable equipment

Should allocate groups based on ability

Not appropriate for training level, i.e., 'too much unfamiliar jargon'

Clinical applications not made clear

Should have featured a small theoretical introduction

Total (negative comments)

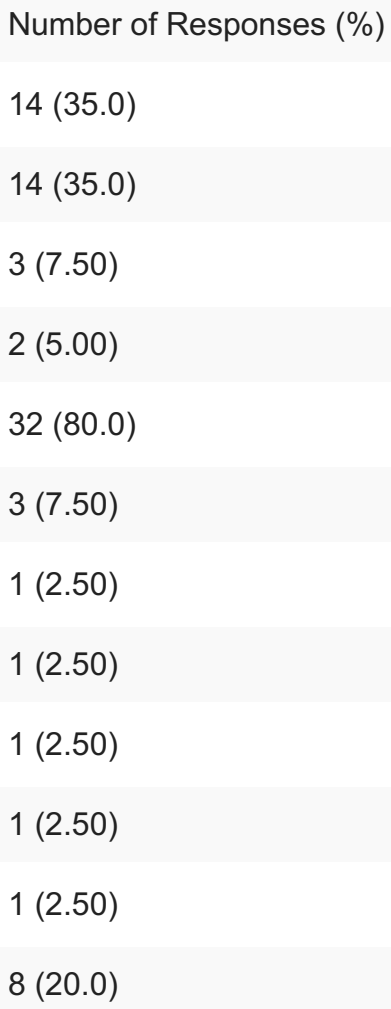

\section{TABLE 3: Feedback Comments for Instructors from Different Workshop Stations for the 2018 Surgical Skills Day}

Table 4 below shows the student feedback comments across the three years on aspects they felt were particularly good about the SSD. 


\section{Cureus}

\section{Category}

"Hands-on" practicality

Variety of specialty stations on offer

Surgeon interaction

Overall organisation of the day

Enjoyment and fun

Fulfillment of dietary requirements

Challenges and Competition

Value for money

Good amount of time provided at each station
Number of Responses (\%)

$42(38.5)$

$28(24.9)$

$11(10.7)$

$6(5.70)$

$5(5.00)$

$5(5.00)$

$4(4.30)$

$3(3.60)$

$2(2.10)$

TABLE 4: Feedback Comments on Aspects of the Surgical Skills Day That Were Particularly Good

Table 5 below details aspects of the SSD across the three years which the students wanted to change. 


\section{Cureus}

\section{Category}

More stations with different specialties

Increase time available at stations

Increase equipment available

Reduce time available at stations

Provide handouts with information

Personal protective equipment required

Increase the number of tutors

Increase the interactivity of certain stations

Adapt sessions to training level

Provide a wider variety of food options

Smaller groups per station

Provide a careers station

Host the event on an alternative day
Number of Responses (\%)

$21(19.6)$

$17(15.9)$

$11(10.3)$

$10(9.35)$

$10(9.35)$

$9(8.41)$

$7(6.54)$

$5(4.67)$

5 (4.67)

$5(4.67)$

$3(2.80)$

$3(2.80)$

$1(0.93)$

\section{TABLE 5: Feedback Comments on Aspects of the Surgical Skills Day That Students}

Wanted to Change

Students were asked to identify a favourite station and then comment as to why they chose that particular station. These comments were coded and grouped into categories. Categories were then assigned percentage values based on the number of respondents that mentioned them in their feedback. Table 6 shows this information.

\section{Plastic Surgery: Tendon Repair}

$\begin{array}{lllll}\text { Year } & \text { Size of Cohort } & \text { Standard Deviation } & \text { Number of Votes as Favourite Station } & \begin{array}{l}\text { Confidence } \\ \text { Interval }\end{array} \\ 2018 & 40 & 1.25 & 17 & 8.64 \text { to } 9.42 \\ 2017 & 27 & 0.834 & 14 & 8.88 \text { to } 9.5\end{array}$

Comments:

Category

Number of Responses (\%)

"Hands-on" practicality: interactivity and enjoyment, developing new skills and techniques, contact time with equipment, putting theory into practice, realism: "it felt real" 


\section{Cureus}

Surgeon interaction: quality of tuition, contact time with surgeons

Relevant to studies

Challenging and competitive aspects

\section{Neurosurgery: Burr Holes}

$\begin{array}{lllll}\text { Year } & \text { Size of Cohort } & \text { Standard Deviation } & \text { Number of Votes as Favourite Station } & \text { Confidence Interval } \\ 2016 & 40 & 1.02 & 13 & 8.56 \text { to } 9.2\end{array}$

Comments:

\section{Category}

"Hands-on" practicality: interactivity and enjoyment, contact time with equipment, putting theory into practice, realism: "it felt real"

Challenging and competitive aspects

Surgeon interaction: contact time with surgeons
Number of

Responses (\%)

$6(46.2)$

$2(15.4)$

\section{Laparoscopic Simulation}

Year Size of Cohort Standard Deviation Number of Votes as Favourite Station

Confidence Interval

$2018 \quad 40$

10

8.50 to 9.30

$2017 \quad 27$

0.834

9

8.50 to 9.13

$2016 \quad 40$

0.947

14

8.49 to 9.07

Category

Number of Responses (\%)

"Hands-on" practicality: interactivity and enjoyment, developing new skills and techniques, contact time with equipment, putting theory into practice, realism: "it felt real"

Challenging and competitive aspects

Surgeon interaction: quality of tuition, contact time with surgeons

Variety of activities on offer

Vascular Surgery: Aortic Re-Anastomosis

$\begin{array}{lllll}\text { Year } & \text { Size of Cohort } & \text { Standard Deviation } & \text { Number of Votes as Favourite Station } & \text { Confidence Interval } \\ 2018 & 40 & 1.43 & 6 & 8.29 \text { to } 9.17\end{array}$

Comments:

Category

Number of

Responses (\%) 


\section{Cureus}

"Hands-on" practicality: interactivity and enjoyment, developing new skills and techniques, time available to develop skills

Challenging and competitive aspects

Surgeon interaction: quality of tuition

\section{ENT: Tracheostomy}

$\begin{array}{lllll}\text { Year } & \text { Size of Cohort } & \text { Standard Deviation } & \text { Number of Votes as Favourite Station } & \text { Confidence Interval } \\ 2018 & 40 & 1.46 & 5 & 7.93 \text { to } 8.83\end{array}$

Comments:

Category

"Hands-on" practicality: putting theory into practice

Relevant to studies

Surgeon interaction: quality of tuition

$1(20.0)$

\section{Suturing}

Year Size of Cohort Standard Deviation Number of Votes as Favourite Station

Confidence Interval

$2018 \quad 40$

1.12

6

8.33 to 9.03

$2017 \quad 27$

1.07

3

7.93 to 8.73

$2016 \quad 40$

1.93

7

7.48 to 8.68

Comments:

Category:

"Hands-on" practicality: interactivity, time available to develop surgical skills with live tissue

$7(43.8)$

Perception of learning useful skills for the future

Surgeon interaction: quality of tuition

Relevant to studies

\section{Orthopaedic Surgery: Dynamic Hip Screw}

$\begin{array}{lllll}\text { Year } & \text { Size of Cohort } & \text { Standard Deviation } & \text { Number of Votes as Favourite Station } & \text { Confidence Interval } \\ 2017 & 27 & 1.58 & 2 & 6.66 \text { to } 7.86 \\ 2016 & 40 & 1.05 & 5 & 8.03 \text { to } 8.67\end{array}$

Comments:

Category

Triggering personal interest in this surgical field

"Hands-on" practicality: interactivity and enjoyment, putting theory into practice

$2(28.6)$ 


\section{Cureus}

Surgeon interaction: quality of tuition

Relevant to studies

$1(14.3)$

\section{Trauma Scenario: Conducting a Primary Survey}

$\begin{array}{lllll}\text { Year } & \text { Size of Cohort } & \text { Standard Deviation } & \text { Number of Votes as Favourite Station } & \text { Confidence Interval } \\ 2016 & 40 & 1.69 & 2 & 6.63 \text { to } 7.67\end{array}$

Comments:

Category

Triggering personal interest in this surgical field

\section{TABLE 6: Numerical Statistics and Feedback Comments for the Different Workshop} Stations that Students Identified as Their Favourite Station

\section{Discussion}

The SSD aims to improve surgical education at medical school and engage undergraduates in surgery at an early stage of their career. This builds enthusiasm for the profession and encourages students to make better-informed career choices.

The SSD provides an informal environment for students to network with surgeons and develops mentor-mentee relationships. Mentorship in surgery is crucial for career development and the benefits of developing such relationships are two-way: mentorship provides personal and career enrichment to the mentee and provides satisfaction and further opportunities for the mentor [11]. Unfortunately, many students view experiences with surgeons as intimidating which is a major barrier to student engagement with the profession [12-13]. Meeting surgeons in a non-clinical setting led by students, such as the SSD, helps reduce levels of intimidation. Student comments (71.5\%) reported positive interactions with the surgeons at the 2018 event (Table 2).

There is cogent evidence describing the benefits of kinaesthesia in optimising learning experiences [14]. The SSD provides kinaesthetic-style learning with "hands-on" practicality, which was deemed the most valuable aspect of the event by $38.5 \%$ of students (Table 4 ). Furthermore, the three highest ranked stations were tendon repair, burr hole drilling, and laparoscopic simulation (Figure 2), selected due to tactile learning opportunities; "hands-on" practicality made up $54.8 \%$ of student comments, as preferential reasons for these three stations (mean of $51.6 \%, 46.2 \%$, and $66.7 \%$ for tendon repair, burr hole drilling, and laparoscopic simulation, respectively) (Table 6 ).

These findings corroborate with previous studies suggesting that personal contact with surgeons, in addition to the acquisition of practical skills, is an important part of learning for undergraduates [15-16]. These learning aspects are the key components of the SSD.

The SSD exposes undergraduates to a variety of practical stations in different surgical specialties. The most valuable aspect of the SSD was reported by $24.9 \%$ of the students to be the 
variety of specialty exposure (Table 4). This exposure facilitates students in identifying a specialty of interest. For example, $50 \%$ and $42.9 \%$ of students reported trauma scenarios and dynamic hip screw as their favourite stations, respectively, due to interest being triggered in the specialty (Table 6). The value of exposing medical students to skills relevant to a particular surgical specialty has been reported in the literature in the context of increasing student engagement in cardiothoracic surgery [17]. In developing a surgical specialty interest, students are more likely to consider a career in surgery. This is evident in our study, with $79 \%$ of students more inclined to pursue a surgical career following the SSD (Figure 1).

In addition, the SSD provides teaching on skin suturing, an interventional procedure mandated by the GMC for all UK graduating medical students [8]. Unfortunately, the UK medical school curriculum leaves many new doctors with a lack of confidence in performing basic suturing techniques [16]. A UK national survey reported $86.5 \%$ of students received inadequate suturing training at medical school, with $21.9 \%$ feeling obliged to pay for additional surgical skills workshops [18]. The SSD addresses this issue by providing a skin suturing station in an organised workshop, teaching students GMC mandated suturing techniques. Students see the value of learning this skill, as $31.3 \%$ of attendees who identified suturing as their favourite station did so because they felt it is a useful skill for future work (Table 6).

In light of the SSD improving undergraduate engagement in surgery through mentorship, practical skills, specialty exposure, and teaching of GMC mandated skills, SCRUBS suggests an analogous event be implemented into the UK medical school curriculum. This is supported by national reviews on the medical school curriculum, as well as our attendees, $100 \%$ of whom would like the SSD to be an annual event and 97\% would like to see practical surgical skills incorporated into the curriculum as shown by Figure $1[3,16]$.

\section{Conclusions}

Surgical teaching provided to undergraduate medical students in the UK is insufficient, with regards to providing experience of practical surgical skills and teaching of GMC mandatory suturing techniques. The SSD is a student-led initiative to address these deficiencies, providing greater specialty exposure in a welcoming environment for students and surgeons to meet. In light of this, the authors suggest the SSD or similar event be integrated into the UK medical school curriculum.

\section{Appendices}




\section{Cureus}

SCRUBS Surgical Skills Day Feedback

\section{SCRUBS Surgical Skills Day (2018)}

We hope you had a great day! Please take the time to complete this feedback form, your certificate of attendance will be sent to you thereafter. We hope to see you at another one of our events soon! - The SCRUBS Committee

Email address *

Valid email address

Gender *
Male
Female
Other

Year of study?*

$1 \mathrm{st}$

2nd

$3 r d$

Intercalator - between 2nd and 3rd

Intercalator - between 3 rd and 4th

Intercalator - between 4th and 5th

FIGURE 3: Feedback form - page 1 


\section{Cureus}

Have you purchased SCRUBS membership this year? *

Yes

No, I was already a member

No, I have not purchased SCRUBS membership

Did you hear about this event from people who attended it last year? ${ }^{*}$

Yes

No

Did you attend last year's event? *

Yes

No

Have you attended another SCRUBS event this academic year? *

Yes

No

Have you previously attended an event solely aimed at teaching surgical skills?

Yes

No

If you answered "yes" to the previous question, please explain what the event was?

FIGURE 4: Feedback form - page 2 


\section{Cureus}

Out of the 5 stations today, which was your favourite?

Suturing station - suturing with pig trotter

Laparoscopic station

Plastics station - tendon repair

ENT station - tracheostomy

Vascular station - pig aortaanastomosis

Why was that (or those) particular station(s) better than the other ones? ${ }^{*}$

On a scale of 1 to 10 , how did you find the suturing with pig trotters

$\begin{array}{llllllllll}1 & 2 & 3 & 4 & 5 & 6 & 7 & 8 & 9 & 10\end{array}$

Terrible

Excellent

Please comment on the suturing instructor(s). What did they do well and what could they improve on?

On a scale of 1 to 10 , how good did you find the ENT station -

$$
\begin{array}{llllllllll}
1 & 2 & 3 & 4 & 5 & 6 & 7 & 8 & 9 & 10
\end{array}
$$

Terrible

Excellent

Please comment on the ENT instructor(s). What did they do well and what could they improve on?

FIGURE 5: Feedback form - page 3 


\section{Cureus}

On a scale of 1 to 10 , how good did you find the laparoscopic station? ${ }^{*}$

$\begin{array}{llllllllll}1 & 2 & 3 & 4 & 5 & 6 & 7 & 8 & 9 & 10\end{array}$

Terrible

Excellent

Please comment on the laparoscopic instructor(s). What did they do well and what could they improve on?

On a scale of 1 to 10 , how good did you find the Plastics station tendon repair?

$\begin{array}{llllllllll}1 & 2 & 3 & 4 & 5 & 6 & 7 & 8 & 9 & 10\end{array}$

Terrible

Excellent

Please comment on the plastics instructor(s). What did they do well and what could they improve on?

FIGURE 6: Feedback form - page 4 


\section{Cureus}

On a scale of 1 to 10 , how good did you find the Vascular station - pig aorta anastomosis?

$\begin{array}{llllllllll}1 & 2 & 3 & 4 & 5 & 6 & 7 & 8 & 9 & 10\end{array}$

Please comment on the vascular instructor(s). What did they do well and what could they improveon?

On a scale of 1 to 10 , how useful did you find being divided into small groups?

$\begin{array}{llllllllll}1 & 2 & 3 & 4 & 5 & 6 & 7 & 8 & 9 & 10\end{array}$

Useless

Extremely useful

Would you say you had enough time for each station? *

Yes

No, could have done with more time

No, it was too long

How would you rate the drinks provided? *

$\begin{array}{llllllllll}1 & 2 & 3 & 4 & 5 & 6 & 7 & 8 & 9 & 10\end{array}$

Terrible

Excellent

FIGURE 7: Feedback form - page 5 


\section{Cureus}

How would you rate the lunch provided? *

$\begin{array}{llllllllll}1 & 2 & 3 & 4 & 5 & 6 & 7 & 8 & 9 & 10\end{array}$

Terrible

Excellent

Overall, how useful did you find the day?

$\begin{array}{llllllllll}1 & 2 & 3 & 4 & 5 & 6 & 7 & 8 & 9 & 10\end{array}$

Useless

Very useful

Following today's event, are you more likely to pursue a career in surgery" Yes

Unsure

No

Would you like to see practical surgical skills incorporated into medical * school curriculum?
Yes
Unsure
No

What aspects were particularly good about the day? *

If you could change one thing, what would it be? *

FIGURE 8: Feedback form - page 6 


\section{Would you want to see the Skills Day become a regular yearly event in the future?}

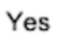

Would you recommend this event to your friends? *

Yes

No

FIGURE 9: Feedback form - page 7

\section{Additional Information \\ Disclosures}

Human subjects: Consent was obtained by all participants in this study. Animal subjects: All authors have confirmed that this study did not involve animal subjects or tissue. Conflicts of interest: In compliance with the ICMJE uniform disclosure form, all authors declare the following: Payment/services info: We received a grant of $£ 100$ from the Medical Defence Union to help run the Surgical Skills Day event in 2018. http://www.themdu.com/ For the 2016 and 2017 Surgical Skills Day events, we received $£ 100$ each year from the Association of Surgeons in Training. http://www.asit.org/ There are no conflicts of interest amongst the coauthors. . Financial relationships: All authors have declared that they have no financial relationships at present or within the previous three years with any organizations that might have an interest in the submitted work. Other relationships: All authors have declared that there are no other relationships or activities that could appear to have influenced the submitted work.

\section{Acknowledgements}

The authors of this article, as well as the following University of Bristol medical students, were involved in the organisation of the Surgical Skills Day events 2016 - 2018: Lelyn Osei Atiemo, Beth Birkbeck, Oscar Guest, Fatima Camp, Niyin Owoso, Paul Rival, Patrick Quinn, Joey Hutchings, Oliver Squires, Tejas Netke, Dhiluni Kandage, Emily Deacon-Elliott, and Sophie Richardson.

\section{References}

1. National Undergraduate Curriculum in Surgery . (2015). Accessed: March 8, 2019: http://www.rcseng.ac.uk/careers-in-surgery/careers-support/national-undergraduatecurriculum-in-surgery/.

2. Lee MJ, Drake TM, Malik TA, O'Connor T, Chebbout R, Daoub A, Wild JR: Has the bachelor of surgery left medical school?--A national undergraduate assessment. J Surg Educ. 2016, 73:655-59. 10.1016/j.jsurg.2016.01.005

3. Hamaoui K, Sadideen H, Saadeddin M, Onida S, Hoey AW, Rees J: Is it time for integration of surgical skills simulation into the United Kingdom undergraduate medical curriculum? A perspective from King's College London School of Medicine. J Educ Eval Health Prof. 2013, 
10:10. 10.3352/jeehp.2013.10.10

4. Zyluk A, Puchalski P, Szlosser Z: The usefulness of the surgical knowledge and skills acquired via the university curriculum for doctors' medical practice several years after graduation. J Surg Educ. 2015, 72:509-14. 10.1016/j.jsurg.2014.10.015

5. Tallentire VR, Smith SE, Wylde K, Cameron HS: Are medical graduates ready to face the challenges of Foundation training?. Postgrad Med J. 2011, 87:590-95.

10.1136/pgmj.2010.115659

6. Wall D, Bolshaw A, Carolan J: From undergraduate medical education to pre-registration house officer year: how prepared are students?. Med Teach. 2006, 28:435-39. 10.1080/01421590600625171

7. Matheson C, Matheson D: How well prepared are medical students for their first year as doctors? The views of consultants and specialist registrars in two teaching hospitals. Postgrad Med J. 2009, 85:582-89. 10.1136/pgmj.2008.071639

8. Tomorrow's Doctors. Outcomes and Standards for Undergraduate Medical Education. (2009). Accessed: March 8, 2019: http://www.ub.edu/medicina_unitateducaciomedica/documentos/TomorrowsDoctors_2009.pdf.

9. Seo H, Eom Y, Kim M, Kim Y, Song B, Song K: A one-day surgical-skill training course for medical students' improved surgical skills and increased interest in surgery as a career. BMC Med Educ. 2017, 17:265. 10.1186/s12909-017-1106-X

10. Karmali R, Siu J, You D, et al.: The Surgical Skills and Technology Elective Program (SSTEP): a comprehensive simulation-based surgical skills initiative for preclerkship medical students. Am J Surg. 2018, 216:375-81. 10.1016/j.amjsurg.2017.09.012

11. Rombeau J, Goldberg A, Loveland-Jones C: Surgical Mentoring: Building Tomorrow's Leaders. Rombeau J, Goldberg A, Loveland-Jones C (ed): Springer, New York; 2010. 10.1007/978-14419-7191-3

12. Hill E, Bowman K, Stalmeijer R, Solomon Y, Dornan T: Can I cut it? Medical students' perceptions of surgeons and surgical careers. Am J Surg. 2014, 208:860-67. 10.1016/j.amjsurg.2014.04.016

13. O'Neill R, Shapiro M, Merchant A: The role of the operating room in medical student education: differing perspectives of learners and educators. J Surg Educ. 2018, 75:14-28. 10.1016/j.jsurg.2017.06.013

14. Shams L, Seitz A: Benefits of multisensory learning. Trends Cogn Sci. 2008, 12:411-17. 10.1016/j.tics.2008.07.006

15. Sutton PA, Mason J, Vimalachandran D, McNally S: Attitudes, motivators and barriers to a career in surgery: a national study of UK undergraduate medical students. J Surg Educ. 2014, 71:662-67. 10.1016/j.jsurg.2014.03.005

16. Davis CR, Toll EC, Bates AS, Cole MD, Smith FC: Surgical and procedural skills training at medical school - a national review. Int J Surg. 2014, 12:877-82. 10.1016/j.ijsu.2014.05.069

17. Haggerty KA, Beaty CA, George TJ, Arnaoutakis GJ, Baumgartner WA: Increased exposure improves recruitment: early results of a program designed to attract medical students into surgical careers. Ann Thorac Surg. 2014, 97:2111-14. 10.1016/j.athoracsur.2014.02.029

18. Rufai SR, Holland LC, Dimovska EO, Bing Chuo C, Tilley S, Ellis H: A national survey of undergraduate suture and local anesthetic training in the United Kingdom. J Surg Educ. 2016, 73:181-84. 10.1016/j.jsurg.2015.09.017 